\title{
Niche analysis of dominant species in alpine desert grassland communities in Qaidam Basin
}

\author{
SUN Jiancai ${ }^{1}$, LI Yonghui ${ }^{1}$, Deng Deting ${ }^{1}$, YANG Sha $^{1}$, WU Yukun ${ }^{1}$, SHI Huilan $^{1 *}$ \\ ${ }^{1}$ College of Eco-Environmental Engineering, Qinghai University, Xining 810016, China
}

\begin{abstract}
Community dominant plants and their ecological niche research is the focus of community ecology research. To explore the niche characteristics of desert dominant plants and the relationship between them and soil factors in Qaidam Basin, and to provide a basis for the construction of desert plant communities and the sustainable management of natural resources in Qaidam Basin. Taking 13 desert plant communities in Qaidam Basin, Qinghai Province as the research objects, this paper analyzed the characteristics of desert plant communities and dominant species based on soil physical and chemical properties, and calculated the niche width and niche overlap of dominant plants. The dominant plants are, Haloxylon ammodendron, Tamarix chinensis, Achnatherum splendens, Poacynum hendersonii, Reaumuria songonica, Phragmites australiss, Sympegma regelii, and Ajania Tenuifolia, Artemisia sphaerocephala, Ceratoides latens, Pearl russianthistle, Scirpustriquter. There were different degree of niche overlap among species in the community. In addition, CCA sequencing showed that different species had different requirements on the environment, and the distribution of dominant species was mainly affected by soil total nitrogen and soil organic matter.
\end{abstract}

\section{Introduction}

Niche refers to the position of a population in time and space in a natural ecosystem and its functional relationship with related populations ${ }^{[1]}$. Niche separation is a way to achieve species coexistence, and reveals the dynamics and causes of interspecific competition and evolution in communities ${ }^{[2]}$

Grinell $^{[3]}$ used the concept of niche in 1917 to divide the spatial units of the environment and the position of a species in the environment. Elton ${ }^{[4]}$ regards ecological niche as the status and function of species in biological community or ecosystem. Hutchinson ${ }^{[5]}$ proposed the concept of $\mathrm{N}$-dimensional niche, emphasizing the impact of various environmental variables on the survival of species. Hutchinson proposed the concept of basic niche and actual niche ${ }^{[4]}$, proposed that a niche is the overall relationship between a plant and its environment. Colinvaux proposed the concept of species niche. After the 1980s, Liu Jianguo and Ma Shijun put forward the extended niche theory ${ }^{[6]}$. Wang Gang ${ }^{[5]}$ defined the generalized species niche as the mapping relationship between environmental variables and species variables.

The quantification of niche characteristics is conducive to the comparison of the range of space occupied by species and the ability to use resources in communities, and the quantitative description of these environmental effects. The niche measurement mainly includes niche width, niche overlap and niche differentiation.

Niche width is one of the quantitative indicators of niche characteristics. When the amount of available resources is limited, the wide niche species have stronger competitive ability, while the narrow niche species have weaker competitive ability. The lack of available resources stimulated the increase of species' niche width, while the niche width narrowed when available resources were abundant.

Niche overlap ${ }^{[7]}$ refers to the degree of common utilization of a certain resource niche by two species, which is measured by measuring the degree of similarity of species in the total resource spectrum. Species using the same resources cannot coexist for a long time, that is, complete competitors cannot coexist. The concept of niche is closely related to the principle of competitive exclusion. The species niche often overlaps within the community.

Niche differentiation ${ }^{[3]}$ refers to the distance between the preferred positions of adjacent competitors on the resource spectrum, and is the dissimilarity of species' ecological niche, which is used to calculate the degree of difference of species' ecological niche.

\section{Materials and methods}

\subsection{Overview of the study area}

Qaidam Basin is a plateau basin, located in the northwest of Qinghai Province, mainly in the Tibetan Autonomous Prefecture of Haixi Mongolian Formation. It is a closed basin surrounded by Kunlun Mountains, Altun Mountains and Qilian Mountains. It is located between $90^{\circ} 16^{\prime} \mathrm{E}$ and $99^{\circ} 16^{\prime} \mathrm{E}$ and between $35^{\circ} 00^{\prime} \mathrm{N}$ and $39^{\circ} 20^{\prime} \mathrm{N}$. The basin

\footnotetext{
*corresponding author: hlshi7701@126.com;

2267290531@qq.com
} 
covers an area of about 240,000 square kilometers. The landforms in the basin are mostly Gobi, bare rock, desert, etc., with little cultivated land resources, sandy soil, extensive permafrost, and less irrigation water. It is a typical inland plateau desert basin with long sunshine, large radiation, large temperature difference, arid climate, long cold winter, short cool summer, and extremely rare annual precipitation.

\subsection{Selection and setting of sample plots}

Through field investigation and investigation, 13 transect zones were randomly set. Different plant types in the transect were set with different quadrates: $1 \mathrm{~m} \times 1 \mathrm{~m}$ quadrate was used for herbaceous plants, $2 \mathrm{~m} \times 2 \mathrm{~m}$ quadrate was used for shrub communities with small plants, and $5 \mathrm{~m} \times 5 \mathrm{~m}$ quadrate was used for shrub communities with large plants. The height, coverage and frequency of each species in the sample square were recorded, and the altitude and geographical location of each sample plot were measured at the same time. Soil samples with 0$20 \mathrm{~cm}$ depth and $20-40 \mathrm{~cm}$ depth were randomly taken in each plot with soil drill to investigate the physical and chemical properties such as soil moisture content and $\mathrm{pH}$.

The dominant species was the main object of this study, including Haloxylon ammodendron, Artemisia sphaerocephala, Artemisia sphaerocephala and Bassia dasyphylla, which were the dominant species in the desert steppe. Phragmites australis, Tamarix chinensis, Salsola asserine, and Nitraria tangutorum, Ceratoides latens, Sympegma regelii, Ceratoides latens and Salsola abrotanoides were the dominant species of the desert shrubs.

\subsection{Data processing}

Importance values indicate the degree of dominance of a species, which can be calculated as follows:

Importance value $(\mathrm{IV})=$ (relative coverage + relative height + relative frequency) $/ 3$

The herb niche width is the ratio of the area occupied by a particular plant to the area of the entire grassland area. The Levins niche width (NB) formula ${ }^{[8]}$ is expressed as follows:

$$
\begin{gathered}
N B_{i}=1 / \sum_{j=1}^{r} P_{i j}^{2} \\
P_{i j}=\frac{n_{i j}}{N_{i}}, \quad N_{i}=\sum_{j=1}^{r} n_{i j}
\end{gathered}
$$

$\mathrm{Nb}_{\mathrm{i}}$ is the niche width value of species $\mathrm{I}, \mathrm{P}_{\mathrm{ij}}$ is the dominance proportion of species I in quadrate $\mathrm{j}, \mathrm{n}_{\mathrm{ij}}$ is the dominance degree of species I in community $\mathrm{j}, \mathrm{N}_{\mathrm{i}}$ is the sum of dominance degree of species I in all quadrates, and $r$ is the number of quadrate.

Hurlbert ${ }^{[8]}$ modified the niche width formula so that the range of the formula was between $[0,1]$, and the modified formula was:

$$
B=\frac{N B_{i}-1}{r-1}
$$

Where, $\mathrm{B}$ is the revised niche width value
The calculation formula of niche overlap (NO) of dominant population is based on the overlapping index Pianka ${ }^{[9]}$ :

$$
N O=\frac{\sum_{j=1}^{N} P_{i j} P_{k j}}{\sqrt{\left(\sum_{j=1}^{N} P_{i j}\right)^{2}\left(\sum_{j=1}^{N} P_{k j}\right)^{2}}}
$$

In the formula, $\mathrm{P}$ is the value of species dominance, $\mathrm{N}$ is the number of quadrants, and the meaning of $\mathrm{P}$ is the same as before

Canonical correspondence analysis (CCA sequencing) is a nonlinear multivariate direct gradient analysis method, which combines analysis with multivariate regression ${ }^{[10]}$.

\section{Results and analysis}

Table 1 statistics the mean value, extreme value and coefficient of variation of each soil factor in different areas and depths, and reflects the degree of dispersion and concentration of each data in the sample site based on this. The horizontal variation of soil can be described by the coefficient of variation. When the coefficient of variation is less than 0.1, it indicates a weak variation, and most of the data are not significantly different. When the coefficient of variation is $[0.1,1]$, it indicates moderate variation and significant difference in some data. When the coefficient of variation was greater than 1, it showed strong variation, and most of the data showed significant differences. The variation coefficient of soil total phosphorus was the smallest in surface layer and deep layer, and the vertical distribution of soil total phosphorus in Qaidam Basin was more uniform, followed by soil total potassium and organic matter. In the horizontal distribution, the coefficient of variation of $\mathrm{K}$ was the smallest, followed by the coefficient of variation of $P$ and $\mathrm{N}$. The coefficient of variation of the surface horizontal distribution of $\mathrm{K}$ was greater than that of the deep horizontal distribution, which may be caused by the surface soil being easily affected by environmental and human factors.

Soil water plant is to maintain normal physiological function and guarantee the life activities of the important conditions, and soil biological, physical and chemical process essential substance, variation coefficient of soil moisture content is 1.10 , in the qaidam basin, the lack of rain is the main cause of this difference, directly reflect the structural of soil, soil bulk density. It is one of the main indicators of soil physical properties. The larger the bulk density, the less fluffy the soil is. Soil bulk density is one of the indexes to measure soil looseness. The change of soil bulk density is small, and the soil texture is more uniform. 
Table 1 summary table of soil ecological factors

\begin{tabular}{|c|c|c|c|c|c|}
\hline Indicators & Soil depth & Max value & Min value & $\begin{array}{l}\text { Coefficient of } \\
\text { variation }\end{array}$ & $\begin{array}{l}\text { Average } \\
\text { value }\end{array}$ \\
\hline \multirow{3}{*}{$\begin{array}{l}\text { Soil total nitrogen } \\
\qquad(\mathrm{g} / \mathrm{kg})\end{array}$} & $0-40 \mathrm{~cm}$ & 1.41 & 0.13 & 0.74 & 0.49 \\
\hline & $20-40 \mathrm{~cm}$ & 1.1 & 0.13 & 0.64 & 0.41 \\
\hline & Average & 1.26 & 0.13 & 1.11 & 0.45 \\
\hline \multirow{3}{*}{$\begin{array}{l}\text { Total phosphorus } \\
\text { (g/kg) }\end{array}$} & $0-20 \mathrm{~cm}$ & 2.38 & 0.91 & 0.24 & 1.44 \\
\hline & $20-40 \mathrm{~cm}$ & 2.18 & 0.87 & 0.27 & 1.43 \\
\hline & Average & 2.28 & 0.89 & 0.01 & 1.43 \\
\hline \multirow{3}{*}{$\begin{array}{l}\text { Total kalium } \\
\qquad(\mathrm{g} / \mathrm{kg})\end{array}$} & $0-20 \mathrm{~cm}$ & 35.15 & 21.53 & 0.12 & 25.77 \\
\hline & $20-40 \mathrm{~cm}$ & 28.79 & 18.79 & 0.11 & 23.50 \\
\hline & Average & 31.97 & 20.16 & 0.07 & 24.64 \\
\hline \multirow{3}{*}{$\begin{array}{l}\text { alkali-hydrolyzable } \\
\text { nitrogen } \\
(\mathrm{mg} / \mathrm{kg})\end{array}$} & $0-20 \mathrm{~cm}$ & 131 & 3 & 0.92 & 38.50 \\
\hline & $20-40 \mathrm{~cm}$ & 76 & 3 & 0.91 & 25.29 \\
\hline & Average & 103.5 & 3 & 0.29 & 31.90 \\
\hline \multirow{3}{*}{$\begin{array}{l}\text { Available P } \\
(\mathrm{mg} / \mathrm{kg})\end{array}$} & $0-20 \mathrm{~cm}$ & 19.1 & 1.2 & 1.15 & 4.86 \\
\hline & $20-40 \mathrm{~cm}$ & 9 & 1 & 0.77 & 3.36 \\
\hline & Average & 14.05 & 1.1 & 0.26 & 4.11 \\
\hline \multirow{3}{*}{$\begin{array}{l}\text { Available K } \\
(\mathrm{mg} / \mathrm{kg})\end{array}$} & $0-20 \mathrm{~cm}$ & 1645 & 31 & 1.14 & 373.17 \\
\hline & $20-40 \mathrm{~cm}$ & 943 & 31 & 0.98 & 254.35 \\
\hline & Average & 1294 & 31 & 0.27 & 313.76 \\
\hline \multirow{3}{*}{$\begin{array}{l}\text { Organic matter } \\
\qquad(\mathrm{g} / \mathrm{kg})\end{array}$} & $0-20 \mathrm{~cm}$ & 22.13 & 0.55 & 0.86 & 8.33 \\
\hline & $20-40 \mathrm{~cm}$ & 16.79 & 0.55 & 0.73 & 6.66 \\
\hline & Average & 19.46 & 0.55 & 0.16 & 7.50 \\
\hline Total salt (g/kg) & $0-20 \mathrm{~cm}$ & 199.53 & 1.59 & 1.42 & 54.98 \\
\hline Water content $(\%)$ & $0-20 \mathrm{~cm}$ & 26.92 & 0.38 & 1.10 & 7.65 \\
\hline $\begin{array}{l}\text { Bulk density } \\
(\mathrm{g} / \mathrm{cm} 3)\end{array}$ & $0-20 \mathrm{~cm}$ & 1.91 & 0.93 & 0.24 & 1.42 \\
\hline
\end{tabular}

\subsection{Distribution characteristics of soil factors}

\subsubsection{Horizontal distribution characteristics of soil factors}

In the horizontal distribution, in the $0-20 \mathrm{~cm}$ surface layer, the total salt content in plot 9, 10 and 11 increased sharply, and the maximum value reached $199.53 \mathrm{~g} / \mathrm{kg}, 144.98$ higher than the average value (Table1). The plot type was the desert shrub of Artemis vulgaris, followed by the saline alkaline land wetland of Scirpus mariqueter + Phrase. The mean value of total salt in all sample plots was 54.98. The variation coefficient of soil total $\mathrm{K}$ was the lowest and its curve was the most gentle (Fig.1a). However, the content of available $\mathrm{K}$ increased in plot 9, 10 and 11 , and reached the maximum value in plot 11(Fig.1b).

In the deep $20-40 \mathrm{~cm}$ soil, the content of total potassium was significantly higher than other indexes, with an average value of $23.50 \mathrm{~g} / \mathrm{kg}$ and a maximum value in the sample plot 15 . The variation coefficient of soil organic matter in deep layer was 0.73 , and the content of organic matter in sample plot 2 and sample plot 11 was the highest. Deep available potassium increased in plot 9, 10 and 11 , and reached $943 \mathrm{mg} / \mathrm{kg}$ in plot 11 . The mean content of available phosphorus was 3.36, and the coefficient of variation was 0.77 .
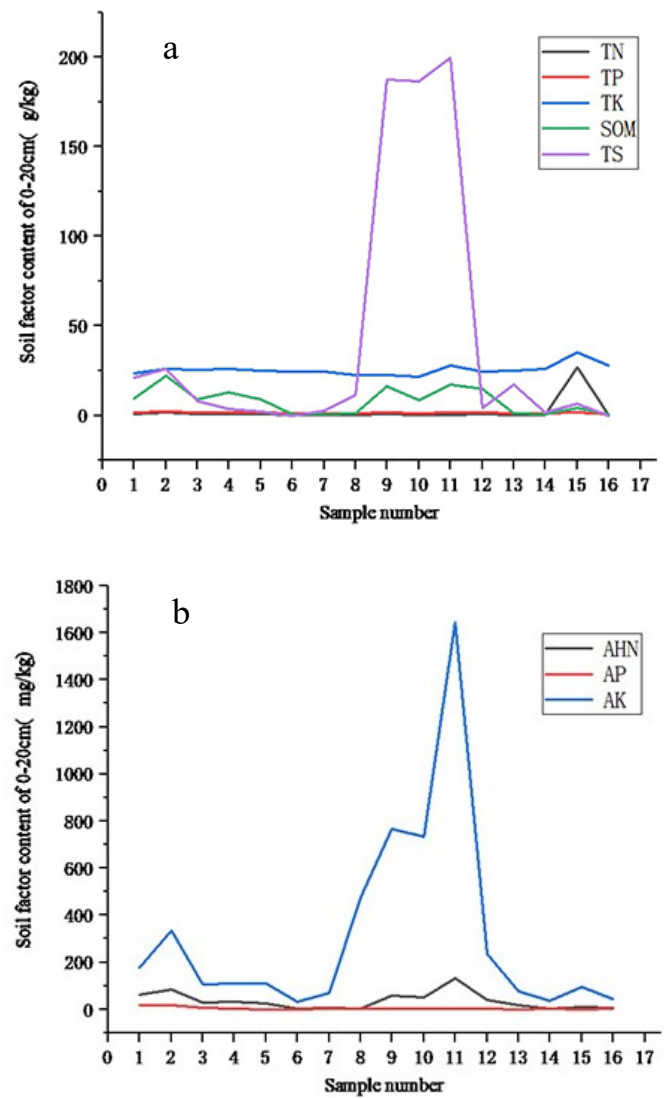

Fig. 1 Distribution characteristics of soil factors at $0-20 \mathrm{~cm}$ level 


\subsubsection{Vertical distribution characteristics of soil factors}

The total nitrogen content in the surface soil of sample plots 1-5, 8-12 was higher than that in the deep soil. The total nitrogen content in the deep soil of sample plots 7, 13 and 16 was higher. The total nitrogen content in the surface soil and the deep soil of sample plots 6 and 15 was the same. The total nitrogen content of surface soil was significantly higher than that of deep soil.

From the average value of each soil layer, the soil total nitrogen content increased with the decrease of soil depth. The total phosphorus content in the surface soil of sample plots 1-2, 6-7, 11, 13 and 15 was high; the total phosphorus content in the deep soil of sample plots 3-5, 8-10 and 16 was higher than that in the surface soil, and the total phosphorus content in the deep soil was high (Fig.2a). From the average value of each soil layer, the soil total phosphorus content decreased with the increase of soil depth. The content of soil organic matter in the surface layer of samples 1-5, 9-12 was higher than that in the deep layer of samples 13, 15 and 16 . The content of soil organic matter in the deep layer of samples 6,7 and 8 was the same as that in the deep layer of samples 6,7 and 8 . According to the average value of each soil layer, the content of soil organic matter decreased with the increase of soil depth, and the content of soil total potassium was evenly distributed in topsoil and deep soil (Fig.2b).
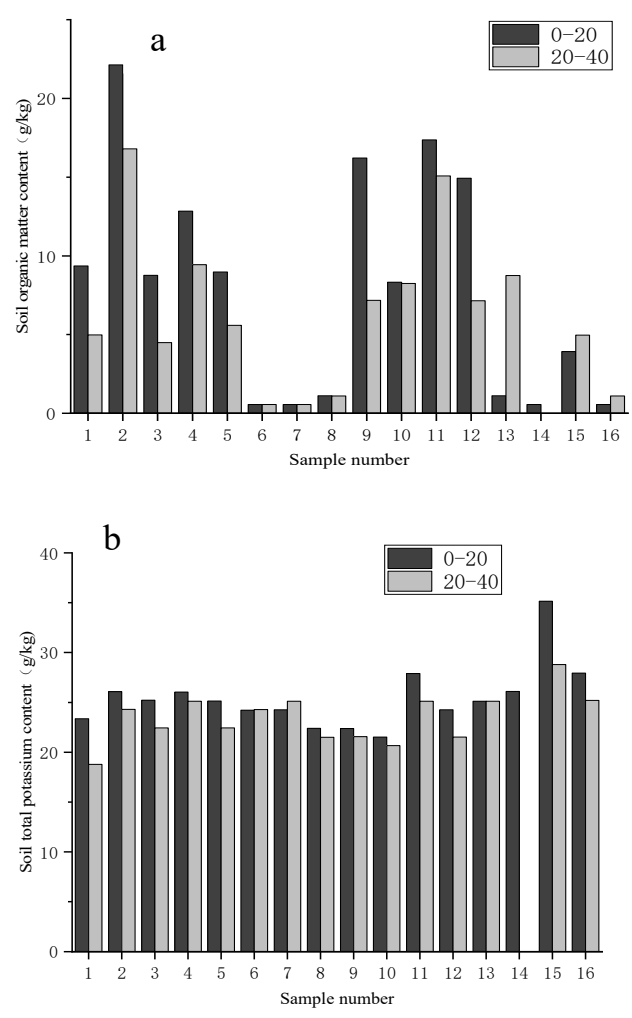

Fig. 2 Vertical distribution characteristics of soil organic matter and total potassium content

\subsubsection{Correlation between soil factors}

There were significant positive correlations between total phosphorus and total nitrogen, total nitrogen and available phosphorus, organic matter and alkali-hydrolytic nitrogen, alkali-hydrolytic nitrogen and available potassium, and available potassium and total salt, with correlation coefficients of $0.82,0.8,0.82,0.77,0.75$, respectively, while there was negative correlation between available phosphorus and total salt. Negative correlation accounted for $14 \%$ and positive correlation accounted for $86 \%$, among which the correlation coefficient above $67 \%$ accounted for $16 \%$, the correlation coefficient between $33 \%$ and $67 \%$ accounted for $42 \%$, and the correlation coefficient between $0-33 \%$ and $33 \%$ accounted for $42 \%$ (Fig.3).

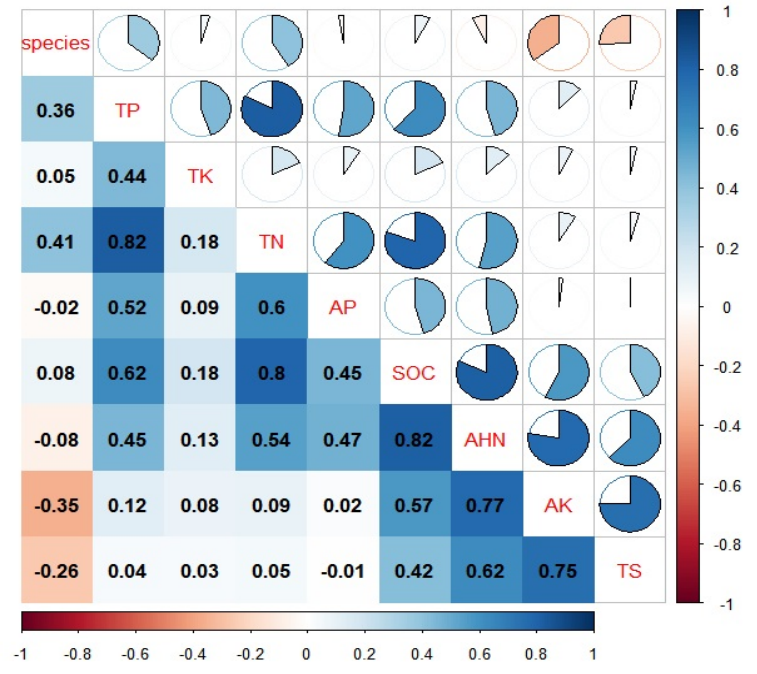

Fig. 3 Correlation analysis diagram of soil factors

\subsection{Niche characteristics of plant communities in Qaidam Basin}

A total of 13 sample plots were set for field plant community investigation, and the geographical locations, community types and dominant species of the sample plots were shown in Table 2.

\subsubsection{Niche width of dominant species}

Niche width is a measure of the status quo of resource and environment utilization of a plant population. The larger the niche width of a population is, the stronger its ability to adapt to the environment will be, and it will be more widely distributed in various environments.

Table 2 is the information table of importance values and niche width of dominant species after the community investigation. According to the analysis of the table, Achnatherum splendens has the largest niche width (IV $=0.15, \mathrm{Bi}=2.565)$, Herba splendens $(\mathrm{IV}=0.12, \mathrm{Bi}=0.693)$ and Herba mongolica $(\mathrm{IV}=0.28, \mathrm{Bi}=0.693)$ has the smallest niche width (Table2). 
Table 2 Plant community questionnaire andImportance and niche width of dominant species

\begin{tabular}{|c|c|c|c|c|c|c|c|}
\hline $\begin{array}{l}\text { Sample } \\
\text { number }\end{array}$ & $\begin{array}{l}\text { Elevation } \\
(\mathrm{m})\end{array}$ & Longitude & Latitude & Dominant species & $\begin{array}{l}\text { Important } \\
\text { value }\end{array}$ & Niche width & Ranking \\
\hline 1 & 3039.22 & $99^{\circ} 3^{\prime} 32^{\prime \prime} \mathrm{E}$ & $36^{\circ} 47^{\prime} 30^{\prime \prime} \mathrm{N}$ & Achnatherum splendens & 0.15 & 2.565 & 1 \\
\hline 2 & 3075.92 & $97^{\circ} 56^{\prime} 31^{\prime \prime} \mathrm{E}$ & $36^{\circ} 10^{\prime \prime} \mathrm{N}$ & Ajania tenuifolia & 0.12 & 0.693 & 10 \\
\hline 3 & 2901.56 & $97^{\circ} 56^{\prime} 31^{\prime \prime} \mathrm{E}$ & $36^{\circ} 3^{\prime} 3^{\prime \prime} \mathrm{N}$ & Artemisia sphaerocephala & 0.36 & 1.099 & 6 \\
\hline 4 & 2757.78 & $96^{\circ} 56^{\prime} 0^{\prime \prime} \mathrm{E}$ & $36^{\circ} 14^{\prime} 13^{\prime \prime} \mathrm{N}$ & Haloxylon ammodendron & 0.29 & 1.386 & 4 \\
\hline 5 & 2746.21 & $94^{\circ} 26^{\prime} 56^{\prime \prime} \mathrm{E}$ & $36^{\circ} 24^{\prime} 6^{\prime \prime} \mathrm{N}$ & Tamarix chinensis & 0.32 & 1.386 & 4 \\
\hline 6 & 2719.41 & $94^{\circ} 15^{\prime} 39^{\prime \prime} \mathrm{E}$ & $36^{\circ} 31^{\prime} 9^{\prime \prime} \mathrm{N}$ & Poacynum hendersonii & 0.38 & 1.098 & 8 \\
\hline 7 & 2720.57 & $94^{\circ} 12^{\prime} 13^{\prime \prime E}$ & $36^{\circ} 33^{\prime} 45^{\prime \prime} \mathrm{N}$ & Phragmites australis & 1.00 & 1.792 & 2 \\
\hline 8 & 2794.83 & $93^{\circ} 14^{\prime} 51^{\prime \prime} \mathrm{E}$ & $36^{\circ} 54^{\prime} 28^{\prime \prime} \mathrm{N}$ & Scripus distigmaticus & 0.28 & 0.693 & 10 \\
\hline 9 & 2802.41 & $93^{\circ} 10^{\prime} 17 " \mathrm{E}$ & $36^{\circ} 54^{\prime} 41^{\prime \prime N}$ & Ceratoides latens & 0.71 & 1.387 & 3 \\
\hline 10 & 3052.69 & $91^{\circ} 57^{\prime} 48^{\prime \prime} \mathrm{E}$ & $36^{\circ} 40^{\prime} 23^{\prime \prime} \mathrm{N}$ & Sympegma regelii & 0.25 & 1.097 & 8 \\
\hline 11 & 2736.98 & $96^{\circ} 13^{\prime} 44^{\prime \prime} \mathrm{E}$ & $36^{\circ} 22^{\prime} 33^{\prime \prime} \mathrm{N}$ & Reaumuria songonica & 0.14 & 1.096 & 9 \\
\hline 12 & 3144.58 & $95^{\circ} 22^{\prime} 9^{\prime \prime} \mathrm{E}$ & $37^{\circ} 48^{\prime} 40^{\prime \prime} \mathrm{N}$ & Pearl russianthistle & 0.16 & 1.099 & 6 \\
\hline
\end{tabular}

\subsubsection{Niche overlap of dominant species}

Niche overlap refers to the similarity between two species in relation to ecological factors. Niche overlap occurs when two species use the same resource or share a certain resource. Table 3 is the statistical table of niche overlap of dominant species.
According to the table analysis, the mean value of niche overlap value was 0.167 , and the niche overlap value was mainly distributed between 0.01 and 0.03 , of which $7.69 \%$ were between 0.01 and 0.02 , and $44.87 \%$ were between 0.01 and $0.03 .80 .77 \%$ of the niche overlap index values were between 0.01 and $0.05,34.62 \%$ of the niche overlap index values were between 0.03 and 0.05 (Table3).

Table 3 Niche overlap of dominant species

\begin{tabular}{|c|c|c|c|c|c|c|c|c|c|c|c|c|}
\hline Species & 1 & 2 & 3 & 4 & 5 & 6 & 7 & 8 & 9 & 10 & 11 & 12 \\
\hline 1 & 1 & & & & & & & & & & & \\
\hline 2 & 0.034 & 1 & & & & & & & & & & \\
\hline 3 & 0.029 & 0.022 & 1 & & & & & & & & & \\
\hline 4 & 0.057 & 0.043 & 0.038 & 1 & & & & & & & & \\
\hline 5 & 0.046 & 0.035 & 0.031 & 0.059 & 1 & & & & & & & \\
\hline 6 & 0.042 & 0.032 & 0.028 & 0.054 & 0.044 & 1 & & & & & & \\
\hline 7 & 0.038 & 0.029 & 0.025 & 0.049 & 0.040 & 0.036 & 1 & & & & & \\
\hline 8 & 0.025 & 0.019 & 0.017 & 0.032 & 0.026 & 0.024 & 0.022 & 1 & & & & \\
\hline 9 & 0.029 & 0.022 & 0.020 & 0.038 & 0.031 & 0.028 & 0.025 & 0.016 & 1 & & & \\
\hline 10 & 0.022 & 0.027 & 0.024 & 0.046 & 0.037 & 0.034 & 0.031 & 0.020 & 0.024 & & & \\
\hline 11 & 0.040 & 0.030 & 0.027 & 0.051 & 0.042 & 0.038 & 0.034 & 0.023 & 0.027 & 0.032 & 1 & \\
\hline 12 & 0.027 & 0.021 & 0.018 & 0.035 & 0.029 & 0.026 & 0.023 & 0.016 & 0.018 & 0.022 & 0.025 & 1 \\
\hline
\end{tabular}

\subsection{Canonical correspondence analysis}

Canonical correspondence analysis (CCA sequencing) is a nonlinear multivariate direct gradient analysis method, which combines analysis with multivariate regression ${ }^{[10]}$. In this study, 13 communities and 61 species were selected for sequencing analysis based on importance values. Canoco 5.0 software was used for CCA sequencing. The first axis value of Tentality of Gradient can be calculated as 12.8 through DCA ranking, so as to conduct CCA ranking. Soil $\mathrm{pH}$ and bulk density decreased from left to right along the CCA1 axis, while soil water content and soil total salt increased from left to right along the first axis Soil total nitrogen and soil organic matter decrease from bottom to top along CCA2. Soil total nitrogen and soil organic matter had the greatest influence on community and species distribution, followed by soil water content and soil pH (Fig.4).

Different species have different requirements on the environment, so they have different distribution differences in the CCA sequence diagram. In the CCA sequence diagram, the species located above the horizontal axis are mainly affected by soil total salt and soil bulk density, while the species located to the left of the vertical axis and below the horizontal axis are mainly affected by soil $\mathrm{pH}$. 

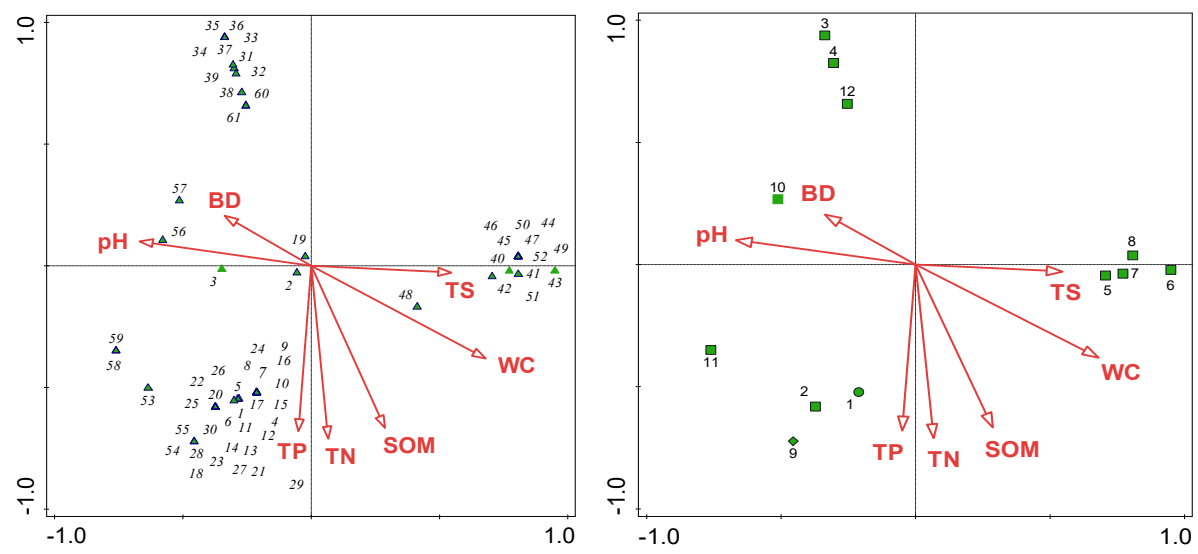

Fig. 4 CCA two-dimensional sequence diagram of environmental factors of species

\section{Conclusion and discussion}

Based on the determination of soil physical and chemical properties and the analysis of niche and CCA sequence of dominant species in Qaidam Basin, this study found that there were different degrees of niche overlap among species in the community. In addition, CCA sequencing showed that different species had different requirements on the environment, and the distribution of dominant species was mainly affected by soil total nitrogen and soil organic matter.

Niche breadth is to measure plant population scale, the utilization of resources and environment NiuHuiHui ${ }^{[11]}$ the plant community in the western qaidam basin found that niche breadth from big to small in turn is: Ceratoides latens, Reaumuria songonica, Achnatherum splendens, Phragmites communis, Salsola abrotanoides, Nitraria tangutorum, Tamarix ramosissima, Haloxylon ammodendron. This is consistent with the results of niche width of dominant species in this paper. And niche breadth of the larger species does not occupy the overlap on the niche overlap value, but in a middle position, achnatherum splendens, for example, it has the highest niche breadth but niche overlap are floating around in 0.2 , and the important value of species niche breadth not necessarily high, reed important value is the largest, but its niche breadth ranked second, These results indicate that these species have obvious response to environmental factors and occupy certain niche under certain conditions. There is no direct linear relationship between niche width and niche overlap of vegetation. Li Jinxiu ${ }^{[12]}$ found that with the aggravation of natural grassland degradation, the niche width and total niche width of dominant species of natural grassland in Qaidam Basin showed a decreasing trend, while the niche overlap value slightly decreased. Different habitat may cause the change of community ecological niche, previous studies have shown that natural environment pressure will gradually eliminated some species, community species richness decreased, and the generalization of the number of can also because the habitat pressure to reduce gradually, cause structure simplification of the community, the community as a whole the resource utilization efficiency and environmental adaptability will abate. Thereby limiting the niche size of the community. Niche overlap reflects the similarity and competition between populations in resource utilization. Higher niche overlap means that populations have similar ecological requirements for environmental resources, and therefore may have intense competition. Most niche studies suggest that a larger niche width is often accompanied by a higher niche overlap. Achnatherum splendens, ramosissima ramosissima, Achnatherum splendens and hemp grandifolium had a large niche width and a high degree of niche overlap.

\section{Acknowledgement}

The study was supported by the following projects: National Key Research and Development Program, China (2017YFC0504800); NSC Promote the Research Cooperation and High-level Talents Training Program with Canada, Australia, New Zealand and Latin America ([2021]109 CSC); Basic Research Project of Qinghai Science and Technology Department, China (2021-ZJ715); National Natural Science Foundation of China(C170201); Plant diversity and interpretation in the Haixi Desert, Qinghai Province, China (2019-STXY-7).

\section{References}

1. Zhu CQ. (1993) Niche Theory and its Application in Forest Ecology. J. Chinese Journal of Ecology, (04): 41-46.

2. Lin KM, Guo YS. (2001) The Research Advances on Niche Theory and its Application. J. Journal of Fujian College of Forestry, 21(3): 283-287.

3. May R. Sun RY, Translation [M]. Beijing: Science press. 1980.

4. Zhang GM, Xie SC. (1997) Development of Niche Concept and Its Perspectives. J. Chinese Journal of Ecology, 16(6):46-51.

5. Wang G, Zhao SL, Zhang PY, et al. (1984) On the Definition of Niche and the Improved Formula for Measuring Niche overlap [J]. Acta Ecologica Sinica, 4(2): 119-127.

6. Liu JG, Ma SJ. Perspective of Modern Ecology [M]. Beijing: Science press.1990. 
7. Abrams P. (1980) Some comments on measuring niche overlap. J. Ecology, 61(1): 44-49.

8. Huang YZ. (1994) Mathematical method in Niche Theory Study. J. Chinese Journal of Applied Ecology, 5(3): 331-337.

9. Thompson K, Gaston K J, Band S R. (1999) Range size, dispersal and niche breadth in the herbaceous flora of central England.J. Journal of Ecology, 87(1): 150-155.

10. Zheng CC, Yi LT, Zhang C, et al. (2015) Interspecific relationship and canonical correspondence analysis of the dominant species in ecological service forest of Jiangshan City in Zhejiang Province. J. Acta Ecologica Sinica, 35(22): 7511-7521.

11. Niu HH, Chen H, Fu Y, et al. (2019) Ecological niche characteristics of desert plants in the eastern Qaidam Basin. J. Acta Ecologica Sinica, 39(08): 2862-2871.

12. Li JX. (2012) Study on the Ecological Niche of Natural Grassland with Different Degraded Degree in Qaidam Basin. J. Journal of Anhui Agri, 40(06): 3362-3363+3688. 